ARTIGOS 



\section{Crise e fome na Alta Idade Média: o exemplo dos capitulários carolíngios}

Marcelo Cândido da Silva*

Resumo: A "crise" é hoje um tema recorrente nas obras de historiadores, economistas, biólogos, geógrafos, sociólogos, politólogos, ambientalistas etc. Isso se deve, em primeiro lugar, à atualidade do fenômeno, seja em sua dimensão econômica (com a estagnação das taxas de crescimento desde 2008 na maior parte dos países ocidentais), ambiental (o aquecimento climático), sanitária (epidemias de H1N1, ébola, Zika etc.), securitária (terrorismo, crime organizado), política (guerras civis, revoluções, conflitos, migrações) e mesmo intelectual (crise da História, crise das Ciências, crise disciplinar). Uma recorrência e uma abrangência que colocam diversos problemas em torno da noção de crise, sua aplicabilidade e seus limites como instrumento analítico. Essa aplicabilidade e esses limites serão discutidos ao longo deste artigo, tendo como pano de fundo a questão das crises alimentares na Alta Idade Média, especialmente no período carolíngio, através da análise do Capitulário de Frankfurt e do Capitulário de Nimègue, publicados durante o reinado de Carlos Magno.

Palavras-chave: Crise. Fome. Capitulários.

\section{Introdução}

Em que pese o interesse atual e crescente pelo tema da crise, a acepção moderna do conceito emergiu lentamente na segunda metade do século XIX (GUERREAU, 2002, p. 369), juntamente

\footnotetext{
* Doutor em Historia Medieval pela Université Lumiere Lyon 2, França. Professor de História Medieval da Universidade de São Paulo - USP. Bolsista de Produtividade em Pesquisa do CNPq - Nível 2. E-mail: candido@usp.br
}

Anos 90, Porto Alegre, v. 24, n. 45, p. 185-207, jul. 2017 
com a História Científica. Fruto das primeiras fissuras do Romantismo, "crise" tornou-se, nas obras de Karl Marx, sinônimo e instrumento de transformação social e histórica. Em seus Grundrisse, recentemente objeto de uma nova tradução no Brasil (MARX, 2011, p. 58), Marx afirma que, na sociedade burguesa, há categorias que permitem simultaneamente compreender a organização e as relações de produção de todas as formas de sociedade desaparecidas, pois essa sociedade ainda carrega consigo "resíduos não superados". De um alcance, portanto, limitado, a "crise" não traria consigo a superação de todos os traços do passado, além de ainda permitir que as formas antigas sejam conhecidas por meio das formas modernas: "[...] a economia burguesa fornece a chave da economia antiga". No âmbito das interpretações materialistas da História, aliás, "crise" adquire um sentido quase rotineiro, que encontrou seu paroxismo na teoria dos ciclos, de Nicolai Kondratieff (KONDRA-TIEFF, 1984). No período entre guerras, porém, um forte sentido de excepcionalidade lhe foi atribuído, o qual se traduziu no tema da "decadência do Ocidente", segundo a expressão consagrada por Oswald Spengler. Nas décadas que se seguiram ao último conflito mundial, enquanto a noção de crise conheceu uma fortuna crítica entre modernistas e especialistas da História Política, houve um nítido recuo em sua utilização pelos historiadores da Antiguidade e da Idade Média (embora os temas "crise da História" e "crise da História Política" tenham encontrado enorme eco entre esses últimos). Os consensos que pareciam existir em relação a certos períodos da História Antiga e da História Medieval, qualificados até então e de forma unânime como períodos de crise, foram desfeitos. É o caso de três crises paradigmáticas: a "crise do Império Romano", o "Ano Mil" e a "crise do século XIV”. Paradigmáticas não apenas por terem produzido quase tantas interpretações quanto obras escritas a respeito - em 1984, foram repertoriadas 210 interpretações sobre a crise do Império Romano (DEMANDT, 1984, p. 493) -, ou por terem produzido longos debates da historiografia contemporânea (o debate Dobb X Sweezy, ou ainda o debate entre "mutacionistas" e "antimutacionistas") mas também - e sobretudo - porque constituíram terrenos de teste e de consolidação de novos métodos e 
de novas interpretações, respectivamente, a paleoclimatologia e a etnogênese.

No que se refere àquele que é provavelmente o tema mais controverso ainda hoje entre especialistas da Antiguidade e da Idade Média, "os destinos do Império Romano", a noção de crise, até os anos 1940 sinônimo de decadência, foi substituída pelas noções de mutação, adequação, transformação. É sintomático que o mais importante projeto coletivo sobre os séculos IV-VII, desde o final do século XX até o momento, tenha se intitulado "Transformations of the Roman World", e não "The end of the Roman World", por exemplo. O mesmo ocorreu com o "Ano Mil": na historiografia da segunda metade do século XX, as noções de crise e de mutação foram duramente colocadas em xeque por historiadores como Dominique Barthélemy, para quem a "mutação do ano mil" nunca ocorreu (BARTHÉLEMY, 1997). No caso da "crise do século XIV", as pesquisas coordenadas por François Menant e Monique Bourin colocaram em xeque a ideia de uma crise universal naquele período. Estudos regionais desenvolvidos no âmbito do projeto sobre "a conjuntura de 1300" mostraram que regiões, algumas vezes distantes entre si em apenas alguns quilômetros, apresentavam situações demográficas, produtivas e alimentares bastante distintas. Esses estudos concluem que a ideia de uma "crise geral do sistema feudal" não é mais apropriada para definir a situação da Europa Ocidental nos séculos XIV e XV (BOURIN; MENANT; TO FIGUEIRAS, 2014).

Esse recuo da crise na historiografia sobre a Antiguidade e a Idade Média deve-se, em primeiro lugar, ao fato de que a noção de crise é vaga e ambígua, como lembra o historiador Alain Guerreau (GUERREAU, 2002, p. 369). Ela encobre situações bastante variadas, períodos de curta e de longa duração, transformações superficiais e mudanças profundas (FELLER, 2006, p. 5-6). O escopo das realidades que a noção pretende abarcar é extremamente amplo, o que ajuda a explicar a elasticidade do seu uso, tanto em obras que sustentam o colapso do mundo romano quanto em outras que questionam a mesma ideia. Nesse sentido, os historiadores buscaram refúgio em outros conceitos, tais como o de "transformação" ou o de "transição". Em segundo lugar, o recuo do marxismo nos meios 
acadêmicos a partir dos anos 1960 teve, entre seus efeitos, um nítido recuo da articulação entre crise, hierarquia e violência. Esta última deixou de ser considerada como algo que conduz à transformação social, para se tornar uma característica imanente do funcionamento das sociedades e, em alguns casos, aspecto simbólico muito mais do que um dado que define a natureza de certas relações sociais.

Por outro lado, se é verdade que os trabalhos publicados ao longo das últimas três décadas têm sustentado a continuidade das construções políticas e econômicas romanas, bem como reduzido de maneira significativa a amplitude da crise demográfica e econômica no século XIV, isso tem ocorrido a partir dos mesmos materiais (textos escritos e vestígios da cultura material) utilizados por aqueles que, há apenas algumas décadas, diziam exatamente o contrário. Não houve, desde o final do século XIX, descoberta alguma, documental ou arqueológica, que possa por si só explicar essa transformação de perspectivas. O cerne da mudança está nas relações dos historiadores com as suas fontes, que, graças à Nova História, aos Estudos Culturais e ao Linguistic Turn, foram desconstruídas e reconstruídas.

Gostaria de elencar outro aspecto pouco considerado, mas que também ajuda a explicar porque o uso da noção de crise entre antiquistas e medievalistas recuou nas décadas que se seguiram à Segunda Guerra. Entre os especialistas de outros períodos, também é possível notar o nítido recuo do tema da decadência. A oposição entre a "continuidade das civilizações", defendida por Fernand Braudel em sua Gramática das civilizações [“...les civilisations sont des continuités... en ce sens où parmi les coordonnées anciennes (certaines) restent valables aujourd'hui encore" (BRAUDEL, 1963, p. 161)], em detrimento da ideia de "suicídio civilizacional", de Arnold Toynbee, é sintomática da mudança do "ambiente intelectual" na Europa no último pós-guerra. Essa oposição ajuda a explicar, ao mesmo tempo, o grande impacto da obra de Braudel e a obscuridade à qual foi condenada a obra de Toynbee na historiografia do pós-guerra. Todavia, a influência daquilo que estou designando aqui de "ambiente intelectual" vai muito além da condenação de certas obras ao sucesso e de outras ao ostracismo. No momento em que o projeto europeu era lançado, tendo como motor a reconciliação franco-alemã, não 
era mais de bom tom a associação entre os bárbaros, a violência sem limites e os habitantes vizinhos do além-Reno. Esse período no qual se situariam as origens das nações europeias havia sido terreno da disputa franco-alemã e haveria de ser também um dos terrenos da reconciliação. As grandes pesquisas coletivas dos últimos 30 anos, realizadas com financiamento da União Europeia, responderam a editais que traziam em seus textos alíneas como "as origens da Europa". Os trabalhos, publicados sobretudo a partir dos anos 1960, e que sustentavam a ideia de que houve uma "coexistência pacífica" entre romanos e bárbaros, ou que associavam as migrações bárbaras (e não mais as invasões) aos primórdios da construção europeia, demonstrariam, caso ainda fosse necessário, que as ferramentas metodológicas e analíticas utilizadas pelos historiadores não constituem categorias refratárias às influências das relações sociais e políticas que elas próprias têm a pretensão de descrever e de explicar. Os percursos historiográficos da noção de crise no segundo pós-guerra emergem tanto da História Intelectual quanto da História Política da Europa no século XX.

Os anos 2000 marcaram um avanço da crise no cenário acadêmico, igualmente perceptível no âmbito da historiografia sobre o final da Antiguidade e o início da Idade Média. Apesar de suas leituras divergentes acerca do período, Bryan Ward-Perkins, Chris Wickham, Jean-Pierre Devroey, François Bougard, Laurent Feller, Régine Le Jan, entre outros, empregam a noção em seus trabalhos. No entanto, a ênfase na decadência, marcante no período entre guerras cedeu lugar a uma visão neutra, senão positiva, da crise, e que se ilustra pela questão colocada no subtítulo do primeiro volume do projeto coletivo Les élites au haut Moyen Âge, publicado em 2006 (e do qual participou a maior parte desses historiadores): "crises et renouvellements". A conclusão de Hans-Werner Goetz é ilustrativa da posição assumida pelos autores do volume:

“[...] houve, sempre, mudanças, perigos, em seguida crises, depois renovações... Entretanto, muitas contribuições [deste volume] trouxeram a prova de renovações a curto prazo das mesmas elites (pessoas e grupos) após (e apesar de) uma crise. Nesse sentido, uma 'renovação' (ou renovações 
permanentes) parecem ter sido mais característicos para a Alta Idade Média do que uma crise" (GOETZ, 2006, p. 487, p. 494-495).

Mais importante ainda: o centro de gravidade das análises deixou de ser uma crise sistêmica tão ampla quanto monolítica e deslocou-se para as suas formas "substantivadas" (crise econômica, crise política, crise alimentar, crise sanitária etc.) e, sobretudo, para o campo das respostas às crises. Esse duplo deslocamento epistemológico é, por um lado, o fruto da constatação de que o conceito de crise é amplo demais, elástico demais, para ser operacional. Por outro, o resultado da introdução de novos conceitos que ajudaram na compreensão das respostas às crises, tais como "Governança".

Isso é particularmente visível nos estudos sobre as crises alimentares. A fome, além da "manifestação mais espetacular da crise", segundo a expressão de Monique Bourin e de François Menant (BOURIN; MENANT, 2011, p. 9), constitui um dos campos de estudos da crise que melhor ilustram a preocupação com os mecanismos de resposta das sociedades. Os principais estudos sobre a fome publicados na segunda metade do século XX, seja sobre a Irlanda em meados do século XIX, o mundo romano antigo, a China do final dos anos 1950 e início dos anos 1960, ou ainda a Etiópia dos anos 1980, interessam-se pelas respostas à fome ${ }^{1}$.

A razão disso é que a fome se tornou, na epistemologia contemporânea, objeto de análise e de definição, e não mais apenas de comparação e de categorização. Essas análises, que são comumente chamadas de "teorias da fome", também têm como objetivo claramente expresso a busca de soluções ao problema. As "teorias sobre a fome" apresentam um quadro de análise que identifica a fome com determinadas causas, e recomendam, então, diferentes formas de ação. A fronteira que separa alguns desses estudos das propostas de políticas públicas é bastante tênue, senão inexistente, como é o caso dos estudos sobre a fome na Etiópia ou no Sudão do Sul. Paradoxalmente, esses estudos "despolitizam" a fome, ao enfatizarem as questões e as soluções técnicas, deixando de lado as conjunturas políticas nas quais as crises alimentares nasceram e se desenvolveram. Nesse sentido, o melhor exemplo são os primeiros 
estudos sobre a fome na Etiópia, que destacavam a seca e as questões ambientais, mas deixavam de lado a guerra civil que atingia o país desde os anos 1960 e que havia se agravado a partir de 1984. A comemoração dos dez anos da fome na Etiópia foi a ocasião para a realização de um colóquio em Adis-Abeba ${ }^{2}$. Apesar de debates acalorados entre especialistas e representantes de organizações humanitárias, houve nítida rejeição da ideia de que a fome de 1984-1985 foi causada pela seca, explicação corrente até então. Papel central foi atribuído ao conflito entre a Etiópia e os separatistas na Eritreia e em Tigré. Os participantes do colóquio também expressaram a opinião de que aspectos técnicos ou gerenciais de prevenção da fome não são os únicos fatores que devem ser considerados, nem mesmo os mais importantes: a atenção dada a aspectos políticos, tais como responsabilidade, participação e controle do processo social e econômico, seria crucial (EDKINS, 2000, p. 8).

\section{Os problemas das fontes}

A ênfase de economistas e sociólogos nas causas da fome e nos meios de ação necessários para debelá-la traz dois problemas para os historiadores. O primeiro é que o estatuto e a natureza dos relatos - fundamentais para a reconstituição das conjunturas políticas - acabaram sendo relegados a segundo plano. O segundo é a dificuldade em identificar qual ou quais são os atores que estão na origem das respostas à fome. As teorias da fome, sobretudo após os anos 1990, têm enfatizado os atores não estatais (as ONGs) ou supraestatais (a comunidade internacional). Aos historiadores das sociedades pré-modernas coloca-se o desafio de pensar as respostas à fome em contextos pré-estatais.

Comecemos pelo primeiro problema. Da mesma forma que a Econometria enxerga os dados quantitativos tanto da Roma Republicana quanto da Nova York moderna como séries que podem ser objeto de comparação, as "teorias da fome" tendem a aproximar os relatos de épocas e de sociedades distintas, buscando deles retirar constantes de causalidade, intensidade e efeitos, sem que se atente aos aspectos formais da construção desses textos ou que se dê a 
devida importância às condições nas quais foram produzidos. Os textos anteriores ao século XIV não oferecem o mesmo número e a mesma qualidade de dados estatísticos que permitem, por exemplo, que se reconstrua a curva de preços de cereais nos mercados urbanos (cf. Livro do Biadaiolo) e a curva de salários dos trabalhadores das cidades. No entanto, esses textos fornecem dados quantitativos que, mesmo fragmentados, podem ser integrados à análise das crises alimentares, ainda que não se possa, a partir deles, construir séries estatísticas. Outro desafio consiste em integrar à análise sobre a fome os aspectos formais desses textos, a autoria, os objetivos de seus autores, seus topoi retóricos.

Há, nas crônicas, nos anais e nas histórias redigidas na Idade Média, uma série de adjetivos que aparecem ao lado da palavra fames ou da palavra carestia, e que são indicadores da vontade de seus autores em marcar a intensidade do fenômeno ${ }^{3}$. $\mathrm{O}$ uso desses adjetivos não corresponde à existência de uma convenção ou de um parâmetro de medida entre os autores das crônicas, simplesmente da vontade de cada autor em chamar a atenção para essa ou para aquela fome. Além disso, do século VIII ao século XI, encontramos nos textos treze referências à incidência de casos de canibalismo de sobrevivência associados a crises alimentares (CURSCHMANN, 1970, p. 82 e ss.), ao passo que há apenas um indício arqueológico que parece remeter à prática em questão, embora esteja longe de ser um indício conclusivo (ABADIE, 2013, p. 185-222). Mais extraordinário ainda é que os relatos de canibalismo anteriores ao século XI utilizam como modelo narrativo o texto de Ezequiel, 5:10. Encontramos, frequentemente, menções nos textos anteriores ao século XIV da morte de um terço da população como consequência da fome $e^{4}$. Tratase, mais uma vez, de uma referência ao que diz o texto de Ezequiel,


referencial importante dos autores que escrevem sobre a fome. Os contextos de crise são lidos à luz da realização das profecias bíblicas. Daí a ideia frequente de que esses textos, bem como os valores neles contidos, não se prestam à análise quantitativa, muito menos à qualitativa.

A existência de topoi retóricos ou ainda as dificuldades de análise, de avaliação e de comparação dos dados quantitativos não 
constituem, de forma alguma, o apanágio dos relatos medievais sobre a fome. Gostaria, a esse respeito, de evocar dois exemplos: os estudos de Margareth Kelleher sobre a associação da figura feminina à fome em memórias e artigos de jornais na Irlanda, nos anos 1850, e em Bengala, na década de 1940 (KELLEHER, 1997, p. 113-114); e também a polêmica em torno do número de vítimas da fome na Ucrânia, que é contemporânea da redação dos primeiros relatos, nos Estados Unidos e na Europa, no início dos anos 1930. As retóricas dos textos e as dificuldades em torno das cifras não são, portanto, provas cabais do "caráter literário" ou da "superficialidade" dos relatos medievais. Como no caso dos textos contemporâneos, essas idiossincrasias também apontam para as disputas políticas em torno da fome.

\section{O exemplo dos capitulários carolíngios}

Gostaria de tratar os dilemas da integração dos textos anteriores ao século XIV à análise da crise alimentar através de dois textos legislativos: o Capitulário de Frankfurt, de 794, e o Capitulário de Nimègue, de 806. Tive a oportunidade de analisar esses textos em artigo publicado na Revista Anos 90, em 2013. No entanto, proponho aqui uma análise distinta, menos baseada nas concepções éticas presentes nesses textos do que na gestão de preços por eles exercida.

O Capitulário de Frankfurt, de junho de 794, um dos mais importantes textos de combate à fome da Alta Idade Média. Apesar de ter sido publicado em um contexto de fome bastante grave e generalizado em todo o reino, pelo que se pode inferir dos dados arqueológicos de que dispomos, o texto menciona apenas a existência de "carestia", o que reforça aquilo que dissemos anteriormente sobre o fato de o vocabulário dos textos não ser um indicador da intensidade das crises alimentares. Além de medidas contra a "carestia", o capitulário também condenava o Adocionismo e o culto das imagens, estipulava um peso justo para a moeda, um preço justo para o pão e para os cereais, atacava a heresia e, finalmente, acordava o perdão por 
"piedade misericordiosa" ao duque Tassilo, que havia se rebelado contra Carlos Magno. O combate à fome não constitui, portanto, um objetivo isolado do texto. Esse combate é parte de um conjunto de medidas que se fundam na justiça e no estabelecimento da ordem.

As respostas do poder político à fome não são, necessária e exclusivamente, respostas à falta de alimentos, mas também iniciativas de restauração da ordem social. O mercado de cereais de Florença, no século XIV, bem documentado graças ao Libro del biadaiolo, de Domenico Lenzi [que nota com precisão os preços dos diversos tipos de grão no mercado de Florença entre 1320 e 1335], é significativo nesse sentido: a preocupação das autoridades da cidade era tanto com a ordem pública quanto com o preço dos grãos. Um exemplo contemporâneo: Jerry Edkins mostrou como as medidas tomadas contra a fome na Etiópia contribuíram para a construção da ideia contemporânea de ordem internacional (EDKINS, 2000, p. 67-102).É precisamente aí que se encontra a armadilha da "eficácia do Estado". Ao medi-la buscando indícios de uma diminuição da intensidade da crise alimentar, deparamo-nos frequentemente com lacunas que não são, necessariamente, a prova de que os poderes públicos na Idade Média eram ineficazes, e sim de que a disponibilidade de bens alimentícios não era a sua única e talvez nem a principal preocupação das medidas que adotavam em situações de crise alimentar.

O fato de o Capitulário de Frankfurt ter sido publicado no contexto de uma assembleia episcopal pareceu a alguns historiadores a prova do desespero dos príncipes carolíngios, incapazes de lidar com uma situação que ultrapassava e muito os meios de que dispunham (DOEHAERD, 1971, p. 58). Trata-se de uma análise que projeta sobre o texto do século VIII uma noção de Estado que lhe é absolutamente estrangeira. Gostaria de discutir, agora, o segundo problema advindo da ênfase das teorias da fome nas respostas ao problema: a identificação dos atores responsáveis por essas respostas. Nas últimas décadas, assistimos à perda da centralidade do Estado no âmbito das abordagens acadêmicas, mas também sua eficiência cada vez mais limitada diante dos desafios da ordem, da desordem e da própria "crise" nas sociedades contemporâneas. A fragmentação do poder na época contemporânea, o fato de que ele se manifesta em redes muito mais do que numa relação unívoca de mando e 
obediência criada a partir do aparato de governo despertou a sensibilidade e o interesse dos historiadores para novas manifestações.

O conceito de Governança é um dos mais sintomáticos produtos desse contexto de fragmentação do poder. Embora tenha surgido em meados do século XX, no âmbito de uma reflexão econômica (COESE, 1937, p. 386-405), mais precisamente sobre as organizações econômicas, o conceito adquiriu rapidamente uma dimensão transdisciplinar, no campo das Relações Internacionais, do Direito, da Geografia, da Ciência Política, da Sociologia e mesmo da História. Essa difusão tem relação estreita com a perda de prestígio da noção de Estado, e também com a constatação de que essa noção é inadequada para a análise de contextos não governamentais ou de sociedades pré-modernas. James Rosenau, um de seus principais teóricos, utiliza governança para discutir a ordem e a transformação sem a atuação de governos. A definição que ele propõe é suficientemente flexível para prescindir da atuação de instituições políticas modernas (ROSENAU, J. N.; CZEMPIEL, E. O., 1992).

A dissociação que se produziu, na historiografia, entre Governança e Governo (leia-se Estado) é semelhante àquela que ocorreu entre Norma e Lei. Em comum entre esses dois fenômenos está o fato de que, na visão dos historiadores contemporâneos, os locais de produção dos ordenamentos sociais e mesmo políticos, antes restritos ao Estado e à Lei, ampliaram-se consideravelmente. Essa ampliação é sintomática das novas configurações do Político, muito mais do que da sua falência. A crise epistêmica do Estado, que mencionei anteriormente, foi fundamental para que os historiadores identificassem manifestações do poder fora dos espaços tradicionais das instituições políticas. Não há dúvida de que isso trouxe benefícios para os estudos medievais. Eis uma coincidência que desempenha um papel central nos estudos medievais hoje: o fato de que a mesma noção que serve para descrever a fragmentação do poder no mundo contemporâneo é apropriada para traduzir as especificidades de sociedades anteriores à centralização monárquica. Graças à noção de Governança, foi possível ampliar o escopo da análise do poder para sociedades nas quais o Estado Moderno ou não existia ou não desempenhava um papel central.

Anos 90, Porto Alegre, v. 24, n. 45, p. 185-207, jul. 2017 
O fato de que a noção de Estado não se presta a descrever as especificidades do poder nos primeiros séculos da Idade Média foi lido como a prova cabal de que as sociedades daquele período eram marcadas pela anarquia. É algo bem distinto o que podemos ver por meio dos textos legislativos da Alta Idade Média. No caso específico do Capitulário de Frankfurt, há, claramente, um princípio que preside o estabelecimento de preços máximos para o pão e para os cereais: o da justiça cristã.

O Capitulário de Frankfurt estabelece que homem nenhum, eclesiástico ou laico, pode vender cereais a preço maior que aquele estabelecido para um módio produzido nos domínios reais: para um módio de aveia, um denário; para um módio de cevada, dois denários; para um módio de centeio, três denários; para um módio de trigo candial, quatro denários. A fixação de um preço máximo também era válida para os cereais vendidos em forma de pão: doze pães de trigo candial, pesando duas libras cada um, deveriam custar um denário; quinze pães de centeio do mesmo peso, um denário; vinte pães de cevada do mesmo peso, um denário; vinte e cinco pães de aveia, igualmente um denário. Estabelecia-se um preço diferenciado e menor (cerca de metade do valor dos cereais mencionados anteriormente) para os cereais oriundos dos domínios reais: dois módios de aveia por um denário, um módio de cevada por um denário; um módio de trigo candial por três denários.

Embora o texto não diga claramente como se chegou aos valores para os diversos tipos de cereais e para o pão, é bastante provável que se levava em conta o custo da produção desses mesmos cereais nos domínios reais (cujos valores de venda também são estipulados no texto), com o acréscimo daquilo que o Capitulário de Nimègue, alguns anos mais tarde, definirá como "justo lucro". O capítulo 4 do Capitulário de Frankfurt exorta aqueles que receberam um benefício (beneficium) real a evitar que os dependentes desses benefícios morram de fome. Uma vez que as necessidades desses últimos fossem satisfeitas, os excedentes poderiam ser vendidos conforme o que o próprio capitulário estabelecia (isto é, os valores do "módio público"): 
"Nosso pientíssimo rei decidiu, com a aquiescência do santo sínodo, que nenhum homem, seja ele eclesiástico, seja laico, venda o grão mais caro que o módio público recentemente estabelecido, seja em tempo de abundância, seja em tempo de carestia, do módio de aveia, um denário, do módio de cevada, dois denários; do módio de centeio, três denários; do módio de trigo candial, quatro denários. Caso se queira vendê-los em [forma de] pão: que se dê doze pães de trigo candial, cada um pesando duas libras, por um denário; pelos de centeio, quinze do mesmo peso por um denário; pelos de cevada, vinte pães de mesmo peso; pelos de aveia, vinte e cinco pães. Quanto aos cereais públicos do senhor rei, caso sejam vendidos: dois módios de aveia por um denário, um módio de cevada por um denário; um módio de trigo candial por três denários. E que aqueles que receberam de nossa parte benefício, cuidem, no que Deus aprouver, para que nenhum servo dependente deste benefício morra de fome; e quanto à medida que exceder à necessidade de seus dependentes, que seja vendida livremente conforme a lei" [Synodus Franconofurtensis (794), c. 4] ${ }^{6}$.

No Capitulário de Frankfurt, a definição de um preço máximo para os gêneros alimentícios era válida tanto para os períodos de abundância quanto para os períodos de carestia: "sive tempore abundantiae sive tempore caritatis". Essa regulamentação era mais do que uma resposta pontual a uma conjuntura de carência de alimentos, mas constitui um conjunto de regras projetadas sobre o conjunto dos sistemas de produção, de troca e de abastecimento. Também no Capitulário de Nimègue, atribui-se aos cereais um preço acima do qual seu comércio é considerado injusto e ilegal:

"Portanto, decidimos, já que neste ano uma fome severa se abateu sobre muitas regiões, que todos os bispos, abades, abadessas, dignitários e condes, assim como seus domestici, bem como seus subalternos e todos os fiéis que recebem benefícios reais fundados tanto sobre bens eclesiásticos quanto sobre os de ordem diversa, providenciem assistência a seus dependentes com os proventos de seu benefício 
e sua família com os recursos de seu alódio. Se, por graça divina, alguém possuir cereais em quantidade excedente à sua necessidade e a de seus dependentes, com os recursos beneficiais ou alodiais, e pretender vendê-los, que não o faça a valor superior a dois denários por módio de aveia, três denários por módio de cevada, três denários por módio de espelta debulhada, quatro denários por módio de centeio, seis denários por módio de trigo candial debulhado. E que este módio seja o que está convencionado que todos devem ter, para que cada um receba uma unidade de medida justa e um mesmo módio" [Capitulare missorum Niumagae (806), 18]7.

Em seu capítulo 18, o Capitulário estabelece que os cereais não poderiam ser vendidos a um valor superior a dois denários por módio de aveia, três denários por módio de cevada, três denários por módio de espelta debulhada, quatro denários por módio de centeio, seis denários por módio de trigo candial debulhado. Como em 794, o capitulário de 806 se preocupava, além do preço, com a quantidade de cereais presentes em cada módio.

\section{Tabela 1: Preços máximos de pão e de cereais em 794 e em 806}

\begin{tabular}{|c|c|c|c|}
\hline $\begin{array}{c}\text { Tipo de } \\
\text { cereal }^{8}\end{array}$ & $\begin{array}{c}\text { Libras de pão } \\
\text { por um denário } \\
\mathbf{( 7 9 4 )}\end{array}$ & $\begin{array}{c}\text { Preço máximo do } \\
\text { módio de cereais } \\
\mathbf{( 7 9 4 )}\end{array}$ & $\begin{array}{c}\text { Preço máximo do } \\
\text { módio de cereais } \\
\mathbf{( 8 0 6 )}\end{array}$ \\
\hline Aveia & 50 libras & 1 denário & 2 denários \\
\hline Cevada & 40 libras & 2 denários & 3 denários \\
\hline Espelta & - & - & 3 denários \\
\hline Centeio & 30 libras & 3 denários & 4 denários \\
\hline Trigo & 24 libras & 4 denários & 6 denários \\
\hline
\end{tabular}

Fonte: DEVROEY, Jean-Pierre. Activité monétaire, marchés et politique à l'âge des empereurs carolingiens. Revue belge de Numismatique et de sigillographie, 161, 2015, p. 177-232, aqui, p. 192.

Há um aumento importante dos preços em relação àqueles estabelecidos pelo Capitulário de Frankfurt, aproximadamente doze

Anos 90, Porto Alegre, v. 24, n. 45, p. 185-207, jul. 2017 
anos antes. A diferença é ainda mais significativa se compararmos com os preços estabelecidos em 794 para os cereais oriundos dos domínios reais. Quer tenha sido o produto de uma curva inflacionária, quer seja a simples constatação do fracasso das medidas adotadas anteriormente (CÂNDIDO DA SILVA, 2013), os valores apresentados no Capitulário de Nimègue indicam que a governança, no período carolíngio, implicava um certo número de operações de cálculo. Não estamos diante de números de fantasia, sem nenhuma relação com a dinâmica da produção e da comercialização. Há, nesse texto, um diagnóstico refinado da situação e talvez também a constatação de que as medidas tomadas anteriormente eram insuficientes, mas certamente uma visão de longo prazo no combate às crises alimentares. O Capitulário de Nimègue define preços e pesos justos para cereais e para o pão, e também o combate à especulação. Todas essas medidas têm por eixo uma noção de justiça das trocas mercantis cuja minúcia é sem precedentes nos capitulários francos: define-se claramente o problema - a usura, a cupidez e a avareza - seus resultados imediatos - a especulação e o turpe lucrum - bem como a solução - o respeito às regras do comércio (negotium). Por outro lado, o capitulário não prevê nenhum tipo de punição àqueles que infringem as regras do comércio. Tais punições são aquelas previstas nos cânones conciliares - documentos eclesiásticos, portanto - para aqueles que cometem o pecado da usura, da avareza, do lucro indevido. A Igreja e a Realeza funcionam aqui como instâncias de Governança, não concorrentes, mas complementares.

Em nenhum momento esses textos representam uma constatação das crises alimentares em termos de um desequilíbrio entre oferta e demanda, e o próprio vocabulário utilizado para descrever essas crises é permeado de referências morais ("praesenti tribulationes", "usura", "avaritia", "turpe lucrum"). Isso os tornaria inúteis do ponto de vista de uma teoria da fome que busca identificar sistematicamente suas causas. Esse vocabulário expõe a existência de problemas mais amplos do que a fome em si e que teriam origem em comportamentos que se oporiam ao princípio da justiça. $\mathrm{O}$ estabelecimento de um peso e de um preço justos, de regras para o bom comércio, bem como a regulamentação da ajuda aos necessitados, constituem meios para vencer as tribulações e restabelecer o equilíbrio da sociedade.

Anos 90, Porto Alegre, v. 24, n. 45, p. 185-207, jul. 2017 
No entanto, esses meios também são operações por meio das quais a produção e as trocas mercantis de bens alimentícios (cereais e pão) são regulamentadas.

A articulação entre a doutrina cristã e a prática econômica na Idade Média não é um tema novo para a historiografia (ver TODESCHINI, 1994; DEVROEY, 2006). Giaccomo Todeschini já havia chamado a atenção para o fato de que elementos de uma "racionalidade econômica” estão presentes nas ideias formuladas pelos autores cristãos (especialmente os Pais da Igreja, os Escolásticos e os Franciscanos), bem como nas práticas da gestão monástica na Idade Média. O que pretendi mostrar é que, por mais que tenham sido orientados por uma percepção moral e cristã acerca da fome e de suas causas, os capitulários carolíngios eram um instrumento de gestão.

Não podemos afirmar peremptoriamente que, ao contrário do que supõem Monique Bourin e François Menant, a parte da alimentação submetida à mercabilidade não era tão marginal, mesmo porque não temos como medir o o impacto desses capitulários. No entanto, é possível afirmar com segurança a existência de uma relação entre justiça e cálculo: a justiça não é um princípio teórico - ou teológico - descolado da concretude das relações sociais. Ele se expressa concretamente na definição dos valores mercantis dos bens alimentícios. A noção de justiça se desdobra em uma ação de regulação e de prevenção para controlar o movimento dos preços do pão e dos cereais. A governança não significa simplesmente a proclamação de um conjunto de princípios, ela concerne a gestão das pessoas e das coisas segundo esses mesmos princípios, o que se traduz, como vimos nos textos legislativos examinados anteriormente, na definição de valores máximos acima dos quais as operações mercantis são consideradas injustas, ainda que esses textos não especificassem as sanções legais às quais estariam submetidos aqueles que praticassem tais ações.

Não sustento, com isso, a existência de uma economia de mercado na Alta Idade Média. A expansão da mercabilidade não é sinônimo de universalização da mercabilidade; a categoria de bens sagrados na Alta Idade Média, bem mais ampla do que aquela que encontramos no século XVIII, excluía terras e vários tipos de bens móveis das práticas de comercialização; além disso, a noção de justiça 
projetada sobre as trocas mercantis, tal como podemos enxergar nos capitulários carolíngios, funcionava como um entrave ao desenvolvimento da liberdade formal de mercado - outra condição, ao lado da universalização da mercabilidade, para a existência de uma economia de mercado no sentido moderno (WEBER, 1991, p. 51). Todavia, o sentido moderno atribuído ao mercado tem evoluído: a ideia de uma liberdade total dos agentes econômicos, ou ainda de uma mercabilidade ampla que atinge pessoas e coisas, têm sido contrastadas com diversos princípios extraeconômicos associados à atividade econômica, como a proteção da natureza, ou ainda a ideia de que nem tudo pode ser objeto de transação mercantil. Essas críticas expõem uma questão candente e atual: a dos limites morais do mercado (por exemplo, SANDEL, 2012). Daí o interesse em avaliarmos com atenção as relações que a Idade Média estabeleceu entre justiça e mercado. É importante lembrar que essa noção "medieval" de justiça obrigava ao cálculo, que era o fato de uma autoridade pública. Aqui, saímos do domínio tradicional do controle sobre pessoas e coisas e passamos a outro, mais complexo, da gestão de coisas e de pessoas. A noção de Governança, muito mais do que a noção de Estado, presta-se a identificar os meandros dessa gestão.

\section{Considerações finais}

Os discursos acadêmicos contemporâneos sobre as crises alimentares dão ênfase às soluções técnicas - o que é compreensível tendo em vista a premência do tema -, mas também relegam a segundo plano a sua dimensão política (EDKINS, 2000, p. xvi-xvii). Manifestação mais espetacular da crise, a crise alimentar é aquela que pode melhor revelar os mecanismos internos das sociedades. Diferentes descrições e diferentes avaliações são testemunhas das perspectivas adotadas pelos diversos atores envolvidos. Os relatos medievais, com suas construções literárias e seus dados, constituem um material bastante propício à análise política da fome. Os textos legislativos que examinei aqui mostram claramente a intenção de seus autores em responsabilizar produtores e, sobretudo, comerciantes pela escassez de pão e de cereais. As "teorias da fome" têm 
como fundamento a ideia de que a fome e os relatos que lhe são contemporâneos constituem, finalmente, o mesmo fenômeno. A contribuição dos historiadores está em poder constatar que se trata de dois fenômenos distintos. Outra dificuldade das chamadas teorias da fome é pretender equacionar e racionalizar toda a diversidade de fatores - climáticos, demográficos, políticos, culturais etc. - que podem se cruzar na origem das crises alimentares. Uma análise que se concentra na construção dos relatos contemporâneos traz a vantagem da compreensão de como a fome foi percebida e, mais ainda, de quais atores sociais foram mobilizados - e de que forma o foram - para responderem à fome.

O fato de que os exemplos que apresentei transitaram com certa frequência entre a época medieval e a época contemporânea pode dar a impressão de que acredito não haver diferenças entre elas, o que é falso, ou de que acredito na necessidade de redefinição das fronteiras entre o moderno e o pré-moderno, o que é verdadeiro. Aquilo que, no caso específico do combate à fome, separa o medieval e o contemporâneo, é menos a ausência e a presença de medidas por parte dos agentes públicos, a eficácia e a ineficácia das medidas adotadas, ou mesmo aquilo que se pretende reconstruir, do que os diversos projetos de construção, bem como a natureza dos agentes que os propõem. Em suma, o estudo das crises medievais, especialmente as crises alimentares, pode nos ajudar a reavaliar as fronteiras entre o moderno e o pré-moderno.

O percurso que desenvolvi aqui só foi possível porque o tema que escolhi, a fome, é, ao mesmo tempo, objeto de análise econômico-sociológica e matéria de relatos históricos. Ao fazer a crítica da abordagem "utilitarista" de alguns economistas e sociólogos preocupados que estão com as causas da fome e com as soluções para ela - não pretendo dissociar as duas ideias. Do contrário, inclusive, não teria evocado a centralidade da noção de Governança para a compreensão dos relatos sobre a fome. Também não pretendi negar aos historiadores toda e qualquer capacidade de influenciar o debate contemporâneo sobre as crises alimentares. O que pretendi salientar foi a importância de se integrar os relatos à análise por aquilo que são: vestígios muitas vezes lacunares, com visões contraditórias 
entre si e comportando dados que nem sempre se prestam à análise serial. Esses relatos permitem que se compreendam as ações dos grupos envolvidos; que se atente para a construção dos discursos sobre a fome; finalmente, que se faça a crítica dos discursos que, à primeira vista, parecem técnicos e mesmo desconexos, mas que se tornam mais claros à medida que os confrontamos com aqueles que os enunciam e com os lugares sociais e políticos que esses últimos ocupam. Ou seja, o que defendo aqui é uma "repolitização" das crises alimentares como objeto de estudo.

\section{CRISIS AND FAMINE IN THE HIGH MIDDLE AGES: THE EXAMPLE OF THE CAROLINGIAN CAPITULARS}

Abstract: The "crisis" is a recurring theme in the works of historians, economists, biologists, geographers, sociologists, political scientists, environmentalists etc. This is due to the actuality of the phenomenon, in many dimensions: economic (with stagnant growth rates since 2008 in most Western countries), environmental (global warming), health (H1N1 epidemic, ebola, Zika etc.), securitarian (terrorism, organized crime), political (civil wars, revolutions, conflicts, migration) and even intellectual (History of the crisis, the crisis of science, etc.). A recurrence and a scope that put many problems surrounding the notion of crisis, its applicability and its limitations as an analytical tool. This applicability and these limits will be discussed in this article, throughout the food crises in the Middle Ages, especially in the Carolingian period, through the analysis of Capitular of Frankfort and Capitular of Nimègue, published during the reign of Charlemagne.

Keywords: Crisis. Famine. Capitular.

\section{Notas}

${ }^{1}$ KINEALY, Christine. The Great Irish Famine. Impact, ideology and rebellion. New York: Palgrave, 2002 (cap. 2: The Government's Response to the Crisis, p. 31-60); THAXTON JR., Ralph. Catastrophe and contention in rural China. Mao's Great Leap forward and the origins of the righteous resistance in Da Fo village. Cambridge: Cambridge University Press, 2008 (Cap. 7: Indignation and frustrated retaliation. The politics of disengagement; Cap. 8: The market comes first. The Economics of Disengagement and the Origins of Reform); Ó GRADA, Cormac.

Anos 90, Porto Alegre, v. 24, n. 45, p. 185-207, jul. 2017 
Famine. A short history. Princeton: Princeton University Press, 2009 (Cap. 7: Public and private action; Cap. 8: The 'Violence of Government'); GILL, Peter. Famine and Foreigners. Ethiopia since Live Aid. Oxford: Oxford University Press, 2010 (Cap. 6: How to prevent a famine); VIRLOUVET, Catherine. Famines et émeutes à Rome des origines de la République à la mort de Néron. Paris: École Française de Rome, 1985 (Cap. 3: L’État romain et les crises frumentaires).

${ }^{2}$ United Nations. Economic Commission for Africa; Relief and Rehabilitation Commission; Inter African Group (1995-03). Famine in Ethiopia: learning from the past to prepare for the future: a symposium. Symposium: Famine in Ethiopia (1995, Mar. 15-18: Addis Ababa, Ethiopia). Addis Ababa: C UN. ECA. Disponível em: <http://hdl.handle.net/10855/1559>.

${ }^{3}$ Como bem observou Pierre Toubert: "Pour le haut Moyen Âge, c'est-à-dire pour la période qui va jusqu'aux $\mathrm{XI}^{\mathrm{e}}-\mathrm{XII}$ siècles, on constate assez paradoxalement que les sources qui forment alors le terrain de manœuvre favori des médiévistes, les recueils de chartes et les cartulaires, n'offrent que peu d'éléments utiles. Il faut nous tourner vers d'autres types de sources. Ce sont en effet les annales et les chroniques - essentiellement monastiques - qui nous livrent les données les plus précieuses. Avec leur goût naturel pour l'extraordinaire et le merveilleux, elles décrivent des crises d'une manière certes souvent stéréotypée mais souvent aussi originale et saisissante. Elles méritent toujours de notre part une analyse critique attentive" (TOUBERT, Pierre. Perception et gestion des crises dans l'Occident medieval. Comptes rendus des séances de l'Académie des Inscriptions et Belles-Lettres, ano 153, n. 4, p. 1497-1513, 2009).

4 "Tanta fames fuit in Boemia, ut tercia pars populi interiret fame" (Cosmae chr. Boemorum SS IX, 75, 10); "Pestilentia et fames in Germania saevit maxime, ubi tertia pars hominum prostrata fuit, et infra unum diem infecti deficiebant" (Joh. Staindelii chr. generale Oefele, I, 515); "quidam de vita desperantes languebant, fere plus quam tertia pars moriebatur, nullus quasi mortem amici sui curabat, quia quod debuit" (Ann. Parch. SS XVI, 608, 35).

5 "A terça parte dos teus habitantes morrerá pela peste e perecerá de fome no meio de ti; outra terça parte cairá à espada em torno de ti; finalmente, a outra terça parte a espalharei a todos os ventos e desembainharei a espada atrás deles". 6 "Statuit piissimus dominus noster rex, consentienti sancta synodo, ut nullus homo, sive ecclesiasticus sive laicus sit, ut nunquam carius vendat annonam, sive tempore abundantiae sive tempore caritatis, quam modium publicum et noviter statutum, de modio de avena denario uno, modio ordii denarius duo, modio sigalo denarii tres, modio frumenti denarii quatuor. Si vero in pane vendere voluerit, duodecim panes de frumento, babentes singuli libras duas, pro denario dare debeat, sigalatius quindecim aequo pondere pro denario, ordeaceos viginti similiter pensantes, avenatios viginti quinque similiterpensantes. De vero annona publica domini regis, si venundata fuerit, de avena modius II pro denario, ordeo den. I, sigalo den. II, frumento 


\section{Marcelo Cândido da Silva}

modius denar. III. Et qui nostrum habet beneficium, diligentissime praevideat, quantum potest Deo donante, ut nullus ex mancipiis ad illum pertinentes beneficium famen moriatur; et quod superest illius familiae necessitatem, hoc libere vendat iure praescripto".

7 "Consideravimus itaque, ut praesente anno, quia per plurima loca fames valida esse videtur, ut omnes episcopi, abbates, abbatissae, obtimates et comites seu domestici et cuncti fideles qui beneficia regalia tam de rebus ecclesiae quamque et de reliquis habere videntur, unusquisque de suo beneficio suam familiam nutricare faciat, et de sua proprietate propriam familiam nutriat; et si Deo donante super se et super familiam suam, aut in beneficio aut in alode, annonam habuerit et venundare voluerit, non carius vendat nisi modium de avena denarios duos, modium unum de ordeo contra denarios tres, modium unum de spelta contra denarios tres si disparata fuerit, modium unum de sigale contra denarios quattuor, modium unum de frumento parato contra denarios sex. Et ipsum modium sit quod omnibus habere constitutum est, ut unusquisque habeat aequam mensuram et aequalia modia".

${ }^{8}$ DEVROEY, Jean-Pierre. La politique annonaire des Carolingiens comme question économique, religueuse et morale. In: L'Alimentazione nell'alto Medioevo. Pratiche, simboli, ideologie. Spoleto: CISAM, 2016, p. 292-353.

\section{Fontes}

Capitulare episcoporum (c.779), ed. A. Boretius, MGH, Capitularia regum Francorum, t. 1, Hanover, 1883, p. 51-52.

Capitulare missorum Niumagae (806), ed. A. Boretius, MGH, Capitularia regum Francorum, t. 1, Hanover, 1883, p. 130-132.

Synodus Franconofurtensis (794), ed. A. Boretius, MGH, Capitularia regum Francorum, t. 1, Hanover, 1883, p. 73-78.

\section{Referências}

ABADIE, I. et al. Traces d'intervention anthropiques sur des restes osseux humains déposés dans un silo du haut Moyen Âge. Site de "La Confiserie", Villiers-le-Bel (Val d'Oise). Revue Archéologique de l'Île-de-France 6, 2013, p. 185-222.

BARTHÉLEMY, D. La mutation de l'an mil a-t-elle eu lieu? Paris: Fayard, 1997.

BOURIN, M.; MENANT, F. Les disettes dans la conjoncture de 1300 en Méditérrannée Occidentale. Paris: École Française de Rome, 2011. 
BOURIN, M.; MENANT, F.; TO FIGUEIRAS, L. (Org.). Dynamiques du monde rural dans la conjoncture de 1300: échanges, prélèvements et consommation en Méditerranée occidentale. Paris: École Française de Rome, 2014.

BRAUDEL, F. Grammaire des Civilisations. Paris: Flammarion, 2013 (1. ed., 1963). BOUGARD, F.; FELLER, L.; LE JAN, R. Les élite au Moyen Âge. Crises et renouvellements. Turnholt: Brepols, 2006.

CÂNDIDO DA SILVA, M. Os agentes públicos e a fome nos primeiros séculos da Idade Média. Varia Historia, v. 32, 2016, p. 779-805.

CÂNDIDO DA SILVA, M. A Economia Moral e o combate à fome na Alta Idade Média. Anos 90, v. 20, 2013, p. 43-70.

COESE, R. The Nature of the Firm. Economica, New Series, 4, n. 16, 1937, p. 386-405.

CURSCHMANN, Fritz. Hungernöte in Mittelalter. Ein Bertrag zur Deutschen Wirtschaftsgeschichte des 8 Bis 13. Jahrhunderts, Leipzig: Scientia, 1970 (1. ed., 1900).

DEMANDT, A. Der Fall Roms. Die Auflösung des römischen Reiches im Urteil der Nachwelt Erweiterte und aktualisierte Neuauflage. Munique: Beck, 1984.

DEVROEY, J.-P. Puissants et misérables. Système social et monde paysan dans l'Europe des Francs (VIe-IXe siècles). Bruxelas: Académie Royale de Bélgique, 2006.

DEVROEY, J.-P. La politique annonaire des Carolingiens comme question économique, religueuse et morale. L'Alimentazione nell'alto Medioevo. Pratiche, simboli, ideologie. Spoleto: CISAM, 2016, p. 292-353.

DOEHAERD, R. Le haut Moyen Âge: économies et sociétés. Paris: P.U.F., 1971.

EDKINS, J. Whose Hunger. Concepts of Famine, Practices of Aid. Minneapolis: University of Minnesota Press, 2000.

GUERREAU, A. Crise. In: GAUVARD, C.; LIBERA, A. de; ZINK, M. (Org.). Dictionnaire du Moyen Áge. Paris: PUF, 2002, p. 369.

KELLEHER, M. The Feminisation of Famine. Durham: Duke University Press, 1997. KONDRATIEFF, N. The Long Wave Cycle. New York: Richardson \& Snyder, 1984. MARX, K. Grundrisse. Manuscritos econômicos de 1857-1858: Esboços da crítica da economia política. São Paulo: Boitempo, 2011.

MORDEK, H., Karls des Großen zweites Kapitular von Herstal und die Hungersnot der Jahre 778/779. Deutsches Archiv für Erforschung des Mittelalters, 61, 2005, p. 1-52.

Anos 90, Porto Alegre, v. 24, n. 45, p. 185-207, jul. 2017 
WARD-PERKINS, Bryan. The Fall of Rome and the End of Civilization. Oxford: Oxford University Press, 2005.

ROSENAU, J. N.; CZEMPIEL, E. O. (Ed.). Governance Without Government: Order and Change in World Politics. Cambridge: Cambridge University Press, 1992.

SANDEL, M. What Money Can't Buy. The Moral Limits of Markets. Londres: Penguin Books, 2012.

TODESCHINI, G. Ilprezzo della salvezza. Lessici medievali del pensiero economico. Roma: Carocci, 1994.

TOUBERT, P. Perception et gestion des crises dans l'Occident médiéval. Comptes rendus des séances de l'Académie des Inscriptions et Belles-Lettres, 153e année, 4, 2009. p. 1497-1513.

WEBER, M. Economia e Sociedade. Brasília: Ed. UnB, 1991, v. 1.

VANDENBERG, Vincent. Fames facta est ut homo hominem comederet: l'Occident médiéval face au cannibalisme de survie (Ve-XIe siècle). Revue Belge de Philologie et d'Histoire, t. 86, fasc. 2, p. 217-282, 2008.

Recebido em: 30/04/2016 Aprovado em: 01/10/2016 
